\title{
Behavior of American alligators monitored by multi-sensor data loggers
}

\author{
Yuuki Y. Watanabe ${ }^{1, *}$, Eric A. Reyier ${ }^{2}$, Russell H. Lowers ${ }^{2}$, Johanna L. Imhoff ${ }^{3,4}$, \\ Yannis P. Papastamatiou ${ }^{3}$ \\ ${ }^{1}$ National Institute of Polar Research, Tachikawa, Tokyo 190-8518, Japan \\ ${ }^{2}$ Kennedy Space Center Ecological Program/InoMedic Health Applications, Kennedy Space Center, Florida 32899, USA \\ ${ }^{3}$ Florida Museum of Natural History, University of Florida, Gainesville, Florida 32605, USA \\ ${ }^{4}$ Present address: Department of Biological Science, Florida State University, Tallahassee, Florida, 32306, USA
}

\begin{abstract}
Fine-scale behavior of crocodilians has rarely been recorded in the field despite the important ecological roles these reptiles play in wetland systems around the world. In this study, we attached multi-sensor data loggers to freeranging American alligators Alligator mississippiensis in the northern Banana River Lagoon, Florida, to record their diving and swimming behavior, diel activity patterns, and horizontal movements. The alligators repeatedly showed shallow, inactive dives (mean depth: $0.75 \mathrm{~m}$, duration: $310 \mathrm{~s}$ ), which may represent sit-andwait foraging for prey. The alligators also showed periodic, submerged swimming events (mean duration: $59 \mathrm{~s}$, swim speed: $0.31 \mathrm{~m} \mathrm{~s}^{-1}$, tail-beat frequency: $0.47 \mathrm{~Hz}$ ). Based on the occurrence of diving and swimming events, and the activity level inferred from acceleration records, the animals tended to be more active during the day than at night, suggesting behavioral thermoregulation. An individual with a global positioning system (GPS) logger attached swam northward along the shore, showing the utility of GPS tracking for this species. This study presents basic information for the natural behavior of crocodilians, an understudied group among aquatic vertebrates.
\end{abstract}

KEY WORDS: Biologging - Crocodilian · Diving · Swimming $\cdot$ Alligator mississippiensis

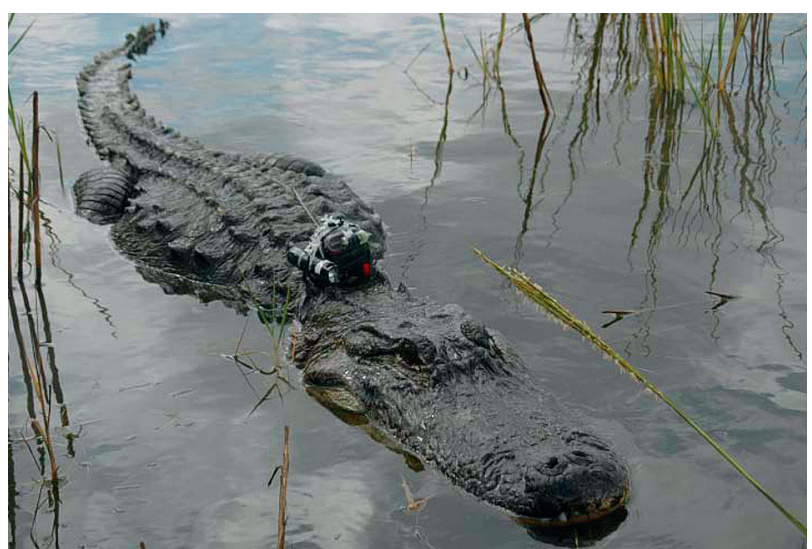

American alligator Alligator mississippiensis (length: $316 \mathrm{~cm}$ ) equipped with a data logger package.

Photo: Yuuki Watanabe

\section{INTRODUCTION}

The recent development of miniaturized datalogging and transmitting tags has made it possible to record various ecological, physiological, and environmental parameters (e.g. dive depth, swim speed, heart rate, body temperature, and ambient temperature) of aquatic animals in their natural habitat (Naito 2004). These tags currently play an essential role in aquatic biology, and have been used for a wide range of vertebrates, including marine mammals, seabirds, reptiles, amphibians, and fishes. However, previous 
studies are heavily biased toward mammals, birds, and fishes. With the exception of sea turtles (especially green Chelonia mydas, loggerhead Caretta caretta, and leatherback Dermochelys coriacea), reptiles and amphibians are under-studied and, hence, their behavior under natural conditions is not well known.

Crocodilians are particularly under-studied, despite the fact that they play important roles in wetland ecosystems as top predators with a broad diet, creators of water pools that affect plant communities, and potential vectors of allochthonous nutrients (Craighead 1968, Bondavalli \& Ulanowicz 1999, Rosenblatt \& Heithaus 2011). Furthermore, some crocodilians are endangered due to past overharvesting and current habitat loss (Thorbjarnarson 1999, Thorbjarnarson \& Wang 1999). At the same time, they can also pose a danger to humans (Langley 2005), and basic, ecological information is needed for effective management. Previous studies of free-ranging crocodilians have focused only on diving behavior detected by pressure sensors (Seebacher et al. 2005, Campbell et al. $2010 \mathrm{a}, \mathrm{b})$ and large-scale (>10 km) horizontal movements detected by acoustic telemetry (Campbell et al. 2010c, Rosenblatt \& Heithaus 2011) or satellite transmitters (Read et al. 2007). Franklin et al. (2009) applied various types of data loggers to crocodilians but presented only snapshots of several types of data they obtained. Therefore, daily activity patterns, which are basic information for the ecological study of animals, are unknown for most crocodilians.

In this study, we attached multi-sensor data loggers to American alligators Alligator mississippiensis in their natural habitat to record their diving depth, swim speed, acceleration, ambient temperature, and global positioning coordinates. This species is widespread in the wetlands of the southeastern United States, and an opportunistic feeder preying e.g. on fishes, turtles, birds, rodents, snails, crayfish, and insects (Delany \& Abercrombie 1986). The fine-scale activity patterns of this species could serve as a model of crocodilian behavior. The specific objectives of this study were to describe the (1) diving behavior, (2) swimming behavior, (3) diel activity patterns, and (4) short-term horizontal movements of American alligators.

\section{MATERIALS AND METHODS}

\section{Tagging}

Fieldwork was conducted in October 2010, with the permission of the Florida Fish and Wildlife Conservation Commission (Permit No. WXO1310) and the National Aeronautics and Space Administration (NASA-KSC IACUC Protocol GRD-06-044). The study site was located in the northern Banana River Lagoon within the Kennedy Space Center security zone, Florida, USA $\left(28.5^{\circ} \mathrm{N}, 80.6^{\circ} \mathrm{W}\right.$; see Fig. 3), where the only robust population of alligators left in the estuarine waters of eastern Florida is found. Although water depth averages only $1.5 \mathrm{~m}$, navigation channels and dredge holes reach depths of 4 and $10 \mathrm{~m}$, respectively. Salinity ranges from 0 to 35 , depending on the location, time of the year, and rainfall amounts, and alligators are found in the full range of salinity.

Four sexually mature alligators (Alligators A to D) were captured in this study. Using a snatch hook (height: $9.7 \mathrm{~cm}$, gap: $3.1 \mathrm{~cm}$ ) on a long pole, alligators were hooked in the water, pulled slowly toward the boat, and restrained on the boat deck at their snouts with a cable tie and tape. Body length was measured, and sex was determined for each individual (see Table 1). Body weight was estimated from the total body length using a published length-weight relationship for this species (Farlow et al. 2005).

To attach data loggers, a scute on the back of the animal (above the fore-legs) was pierced using an electric drill after 3 to $4 \mathrm{ml}$ of a $2 \%$ lidocaine solution was injected subcutaneously around the scute to numb the area. A plastic cable (4 $\mathrm{mm}$ in width) was passed through the hole, and data loggers (described in the following paragraph) along with an instrument-recovery package (i.e. time-scheduled release mechanism [Little Leonardo, Japan], float, and VHF transmitter; Watanabe et al. 2004) were attached via the cable before each animal was released into the water. The cable, connected to the release mechanism by an insulated wire, was severed by an electric charge $48 \mathrm{~h}$ after setup so that the whole package was detached. The package subsequently floated to the surface where the VHF signal could be detected. The total weight of the package (data loggers and recovery system included) was 140 to $280 \mathrm{~g}(<0.5 \%$ of the estimated body weight of the animals), depending on the type of loggers. The buoyancy of the package was 0.5 to $0.8 \mathrm{~N}$ in the water.

Three types of data loggers were used in this study. The W380-PD3GT (21 $\mathrm{mm}$ in diameter, $117 \mathrm{~mm}$ in length, $60 \mathrm{~g}$; Little Leonardo) recorded depth, swim speed (measured by a propeller sensor), and ambient temperature at $1 \mathrm{~s}$ intervals, and tri-axial acceleration (along lateral, dorso-ventral, and longitudinal axes) at 1/32 s intervals. The W1000-3MPD3GT (26 mm in diameter, $175 \mathrm{~mm}$ in length, $135 \mathrm{~g}$; Little Leonardo) recorded tri-axial geomagnetic data at $1 \mathrm{~s}$ intervals, 
in addition to all parameters recorded by the W380PD3GT (geomagnetic data were not used in this study). The GPL20 (49 $\mathrm{mm}$ in width and length, $21 \mathrm{~mm}$ in depth [with rounded corners], $61 \mathrm{~g}$; Little Leonardo) recorded global positioning system (GPS) coordinates at $1 \mathrm{~s}$ intervals. Both the 3MPD3GT and GPL20 models were attached to Alligators A and C, and the PD3GT logger was attached to Alligators B and $\mathrm{D}$, according to the availability of the loggers at the time of deployment (see Table 1). However, the GPL20 did not function for Alligator A due to mechanical failure.

\section{Data analysis}

Behavioral data were analyzed using the software Igor Pro (WaveMetrics) with the package Ethographer (Sakamoto et al. 2009). On the basis of the resolution of the depth sensor $(0.25 \mathrm{~m}$ for the 3MPD3GT and $0.09 \mathrm{~m}$ for the PD3GT), a dive was defined as any excursion below the surface to a depth of $\geq 0.5$ and $\geq 0.2 \mathrm{~m}$ for the 3MPD3GT-attached individuals and the PD3GT-attached individuals, respectively. Relative swim speed, recorded as the number of revolutions per second of a propeller sensor, was converted to actual swim speed $\left(\mathrm{m} \mathrm{s}^{-1}\right)$ based on a previous calibration experiment (Watanabe et al. 2008). Tail-beat frequency $(\mathrm{Hz})$ during swimming was examined from acceleration records. It was defined as the number of tail beat cycles, from one extreme lateral position back to the original position, per second. The pitch angle of the animal (i.e. angle between the long axis of the animal's body and the horizontal) was estimated from the longitudinal acceleration records by filtering out high-frequency signals. Positive pitch indicated a head-up posture and negative pitch indicated a head-down posture. Because setting the logger exactly parallel to the axis of an alligator's body was difficult, the pitch values recorded just before release (when the animal was held horizontally on the boat) were corrected to $0^{\circ}$.

To examine possible diel activity patterns, relative activity level was quantified with the help of tri-axial acceleration records using overall dynamic body acceleration (ODBA, in $g$ ) (Wilson et al. 2006). ODBA is the sum of the absolute values of dynamic acceleration (approximated by high-frequency components of the acceleration records) along the 3 axes, and is correlated with oxygen consumption rates in a variety of animals in the laboratory (e.g. Halsey et al. 2009). While ODBA has never been calibrated for crocodilians, we did not anticipate complications with the data collected. We were primarily interested in relative changes in ODBA over time within an individual, and not absolute values that could be used to estimate field metabolic rates. Daytime and nighttime were defined based on local sunrise $(07: 29 \mathrm{~h})$ and sunset times $(18: 46 \mathrm{~h})$ for that time of year. ODBA was below $0.07 \mathrm{~g}$ when the animals showed no movements (based on acceleration and depth records). Therefore, the threshold of $0.07 \mathrm{~g}$ was used to distinguish active periods from inactive periods.

The behavioral records were statistically examined using $t$-test, with the significance level set at $\mathrm{p}<0.05$. Means $( \pm \mathrm{SD})$ are reported.

\section{RESULTS}

The packages deployed on Alligators B, C, and D were released as programmed and recovered from the water's surface. The package deployed on Alligator A was not released for some unknown reason; however, the individual was located via VHF radio signals and recaptured, and the package was then recovered. A total of $184 \mathrm{~h}$ of behavioral data from the PD3GT and 3MPD3GT loggers was obtained from the 4 individuals (see Table 1). In addition, GPS coordinates were obtained from the GPL20 logger for the initial $7.7 \mathrm{~h}$ for Alligator C.

From the records of the PD3GT deployed on Alligators $B$ and $D, 72$ dives $(\geq 0.2 \mathrm{~m})$ were detected, with a mean depth of $0.5 \pm 0.2 \mathrm{~m}$ and a mean duration of $332 \pm 277 \mathrm{~s}$ (Fig. 1A, Table 1). Alligator B made 4 relatively deep dives $(1.4 \mathrm{~m}$ for $57 \mathrm{~s}, 3.7 \mathrm{~m}$ for $68 \mathrm{~s}, 1.5 \mathrm{~m}$ for $17 \mathrm{~s}$, and $3.7 \mathrm{~m}$ for $59 \mathrm{~s}$ ) just after release, presumably as an escape response; these dives were excluded from the analyses. From the records of the 3MPD3GT deployed on Alligators A and C, 136 dives $(\geq 0.5 \mathrm{~m})$ were detected, with a mean depth of $0.9 \pm$ $0.4 \mathrm{~m}$ and a mean duration of $271 \pm 206 \mathrm{~s}$. The maximum dive depth recorded in this study was $3.2 \mathrm{~m}$, and that dive lasted for $280 \mathrm{~s}$. The number of dives detected varied remarkably (3 to 133) among individuals, despite similar recording periods (44 to $49 \mathrm{~h}_{\text {; }}$ Table 1). Most dives were recorded in the daytime (182 of 208 dives) or early nighttime (earlier than $20: 30 h ; 24$ of 208 dives), with only 2 dives recorded in the middle of the night $(0: 00-2: 00 \mathrm{~h})$.

Most dives (193 of 208) were inactive dives with a flat depth profile, swim speed below the stall speed of the sensor $\left(0.16 \mathrm{~m} \mathrm{~s}^{-1}\right.$ for PD3GT [Alligators B and D] and $0.06 \mathrm{~m} \mathrm{~s}^{-1}$ for 3MPD3GT [Alligators A and C]), horizontal pitch angle, and few recorded tail-beat 


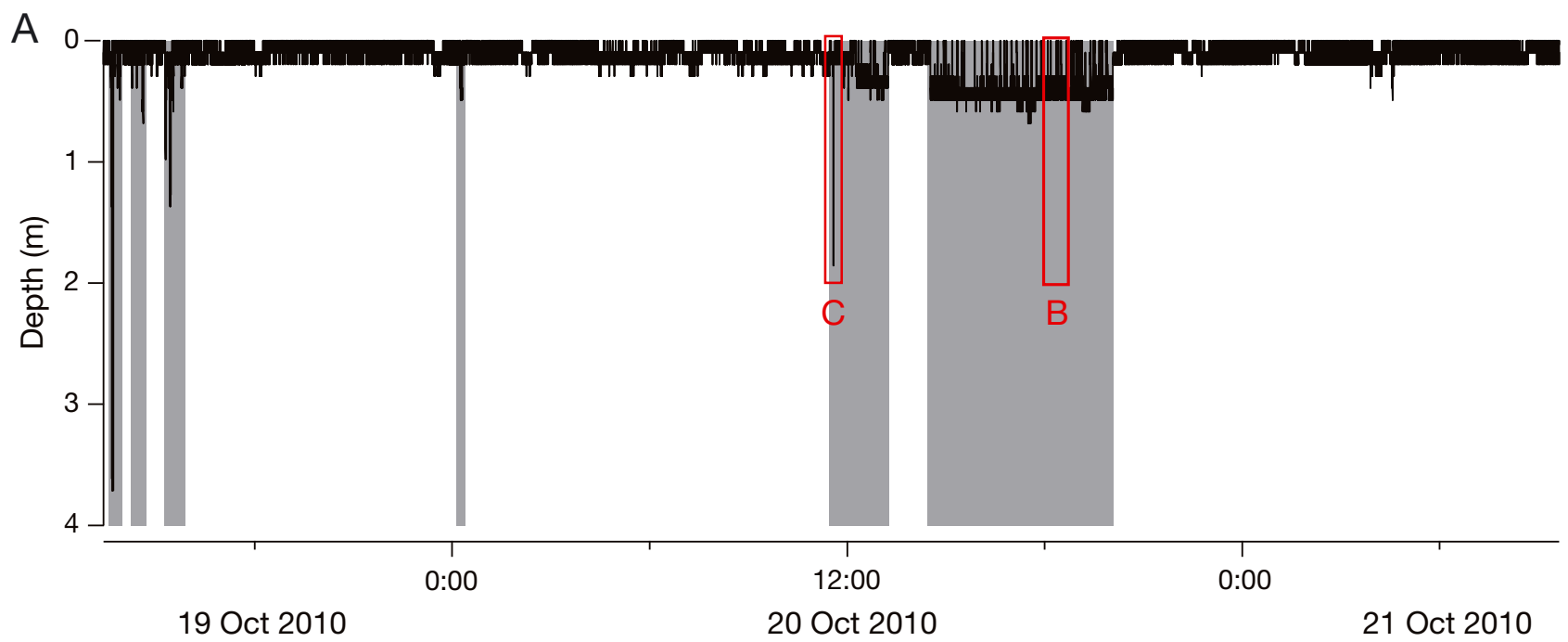

B

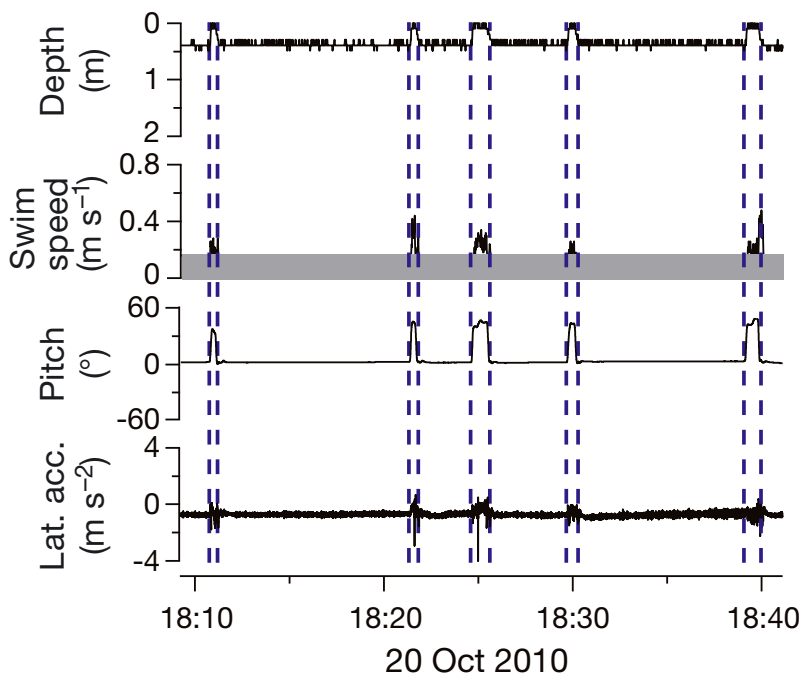

D

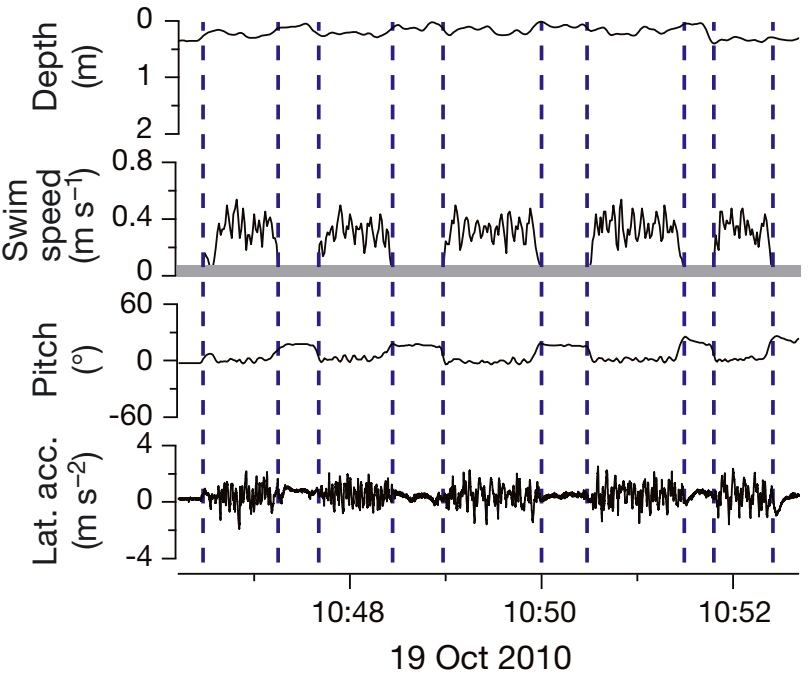

C
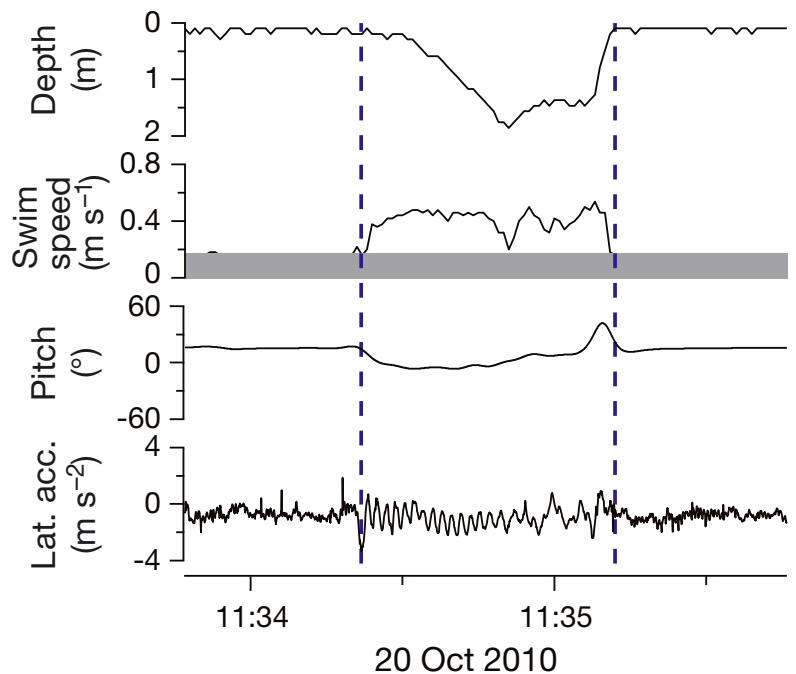

Fig. 1. Alligator mississippiensis. Diving and swimming behavior of American alligators. (A) The entire $44 \mathrm{~h}$ record of depth for Alligator B. Grey bars represent dives. Red rectangles highlight examples of (B) repeated inactive dives and (C) an active dive by Alligator B. (D) Periodic, submerged swimming events by Alligator A. Depth, swim speed, pitch angle, and lateral accelerations (indicative of tail beats) are shown in (B-D). Grey horizontal bars on swim speed represent the stall speed of the sensor. Blue dashed vertical lines separate dives and surfacing periods in (B) and (C), and swimming phases and non-active phases in (D) 
Table 1. Alligator mississippiensis. Descriptive information on 4 American alligators and their diving behavior. Alligators were equipped with different logger models for $2 \mathrm{~d}$

\begin{tabular}{|c|c|c|c|c|c|c|c|c|c|c|c|c|}
\hline $\begin{array}{l}\text { Indi- } \\
\text { vidual }\end{array}$ & Sex & $\begin{array}{l}\text { Total } \\
\text { length } \\
(\mathrm{cm})\end{array}$ & $\begin{array}{l}\text { Estimated } \\
\text { weight } \\
(\mathrm{kg})\end{array}$ & $\begin{array}{l}\text { Logger } \\
\text { attachment } \\
\text { date }\end{array}$ & Logger & $\begin{array}{l}\text { Deployment } \\
\text { duration } \\
\text { (h) }\end{array}$ & $\begin{array}{c}\text { No. } \\
\text { of } \\
\text { dives }\end{array}$ & $\begin{array}{r}\text { Dive de } \\
(\mathrm{m}) \\
\text { Mean } \pm \mathrm{SD}\end{array}$ & $\begin{array}{l}\text { pth } \\
\text { Max. }\end{array}$ & $\begin{array}{c}\text { Dive dura } \\
\text { (s) } \\
\text { Mean } \pm \mathrm{SD}\end{array}$ & $\begin{array}{l}\text { tion } \\
\text { Max. }\end{array}$ & $\begin{array}{l}\text { Mean } \\
\text { temp. } \\
\left({ }^{\circ} \mathrm{C}\right)\end{array}$ \\
\hline A & $\mathrm{F}$ & 248 & 56 & 19 Oct 2010 & $3 \mathrm{MPD} 3 \mathrm{GT}+\mathrm{GPL} 20^{\mathrm{a}}$ & 49.3 & 133 & $0.8 \pm 0.4$ & 3.2 & $276 \pm 206$ & 968 & 24.5 \\
\hline B & $\mathrm{M}$ & 304 & 114 & 19 Oct 2010 & PD3GT & 43.7 & 68 & $0.6 \pm 0.2$ & 1.9 & $338 \pm 281$ & 1262 & 24.3 \\
\hline $\mathrm{C}$ & $\mathrm{M}$ & 316 & 130 & 26 Oct 2010 & 3MPD3GT+GPL20 & 45.6 & 3 & $1.3 \pm 0.6$ & 1.9 & $40 \pm 7$ & 47 & 27.4 \\
\hline $\mathrm{D}$ & M & 292 & 99 & 26 Oct 2010 & PD3GT & 45.4 & 4 & $0.5 \pm 0.2$ & 0.8 & $235 \pm 185$ & 498 & 26.8 \\
\hline
\end{tabular}

activities during the bottom phase (Fig. 1B). These dives were repeated in Alligators A (up to 51 times) and B (up to 45 times) and were interrupted by surfacing periods (mean duration: $48 \mathrm{~s}$ ). The rest of the dives (15 of 208) were active with a mean swim speed of $0.35 \mathrm{~m} \mathrm{~s}^{-1}$ and tail-beat frequency of $0.58 \mathrm{~Hz}$ (Fig. 1C). Active dive durations were significantly shorter than inactive dive durations ( $38 \pm 18$ vs. $310 \pm$ $232 \mathrm{~s}$, respectively; $t_{206}=4.37, \mathrm{p}<0.0001$ ).

Periodic, submerged swimming events were observed for Alligators A (32 events) and C (25 events), in which the animals alternated swimming phases (mean duration: $51 \mathrm{~s}$ ) and non-active phases (mean duration: 47 s) (Fig. 1D). Alligator A showed 6 rela- tively long swimming phases (duration: 244, 80, 173 , 155,77 , and 69 s) just after release, presumably as an escape response; these swims were excluded from the analyses. The longest swim recorded in this study was $116 \mathrm{~s}$. During the swimming phase, pitch angle was nearly horizontal, mean speed was $0.31 \mathrm{~m} \mathrm{~s}^{-1}$ and tail-beat frequency was $0.47 \mathrm{~Hz}$. During the nonactive phase, pitch angle was positive (i.e. upward), indicating that the animals were breathing at that time. Most (52 of 57) swimming events were recorded in the daytime.

The 4 alligators were active (i.e. showing ODBA > $0.07 \mathrm{~g}$ ) during 28.8 (Alligator A), 22.4 (B), 27.1 (C), and $2.3 \%$ (D) of their respective total time records
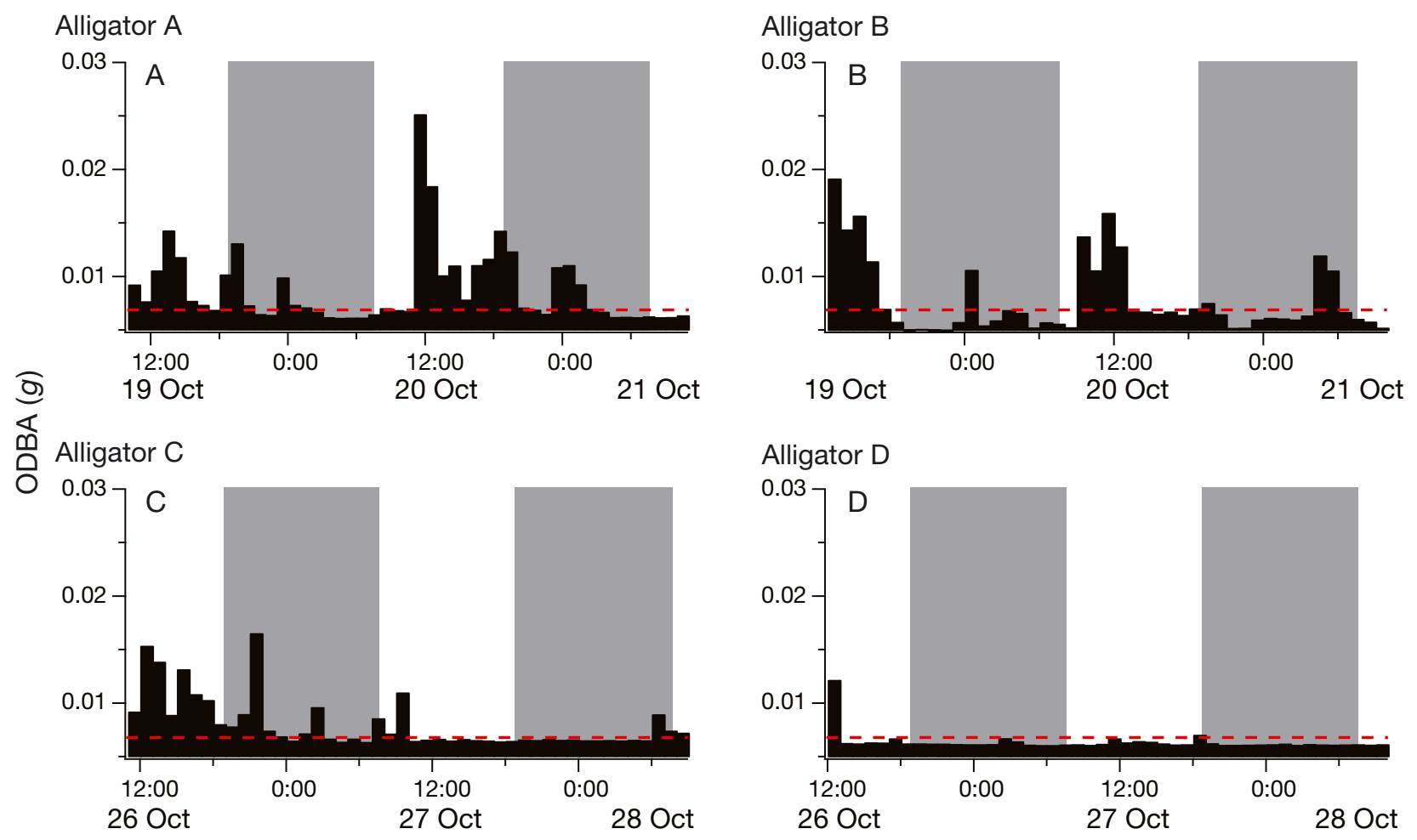

Fig. 2. Alligator mississippiensis. Changes in average overall dynamic body acceleration (ODBA; indicative of relative activity level, calculated as the sum of the absolute values of the dynamic acceleration along the 3 axes) per hour over the entire recording periods for Alligators A to D. Nighttime is indicated by grey bars. Red dashed horizontal lines denote the threshold between active and non-active periods 


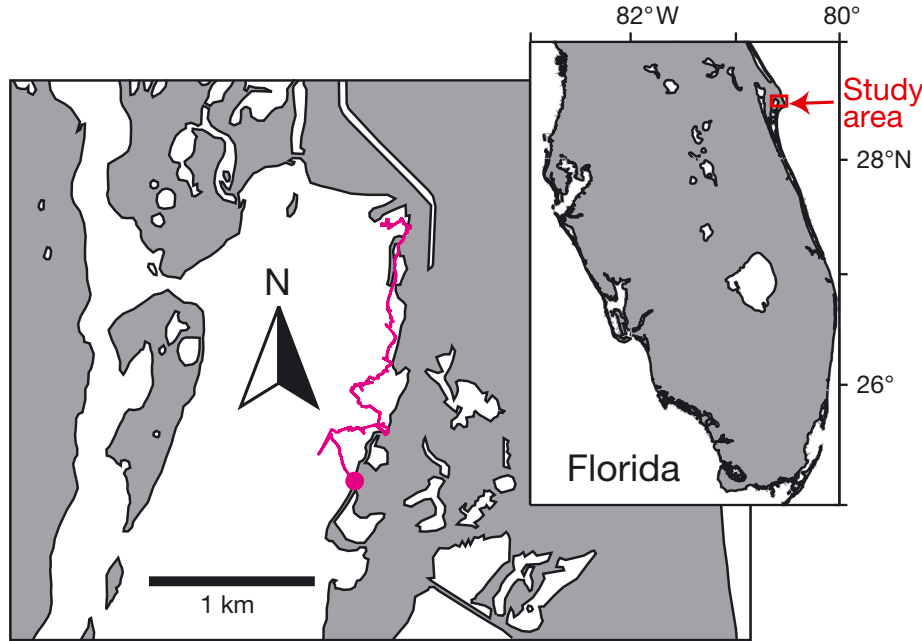

Fig. 3. Study area and GPS track of Alligator C for $7.7 \mathrm{~h}$. Circle on the track: release point of the animal

(Fig. 2). Relative activity levels based on an average ODBA per hour were significantly higher during the day than at night for Alligators $\mathrm{A}\left(t_{47}=-2.63, \mathrm{p}<0.05\right)$ and $\mathrm{B}\left(t_{43}=-3.31, \mathrm{p}<0.005\right)$, whereas activity levels were not significantly different between day and night for Alligators $C\left(t_{44}=-1.70, \mathrm{p}=0.096\right)$ and $\mathrm{D}\left(t_{44}\right.$ $=-1.68, p=0.10$ ). These results may reflect the fact that all individuals were released in daytime, and that some individuals showed relatively high activity levels for a few hours after their release (Fig. 2). To address this possibility, the data were reanalysed, excluding the initial $6 \mathrm{~h}$ of data. In this case, activity levels were significantly higher during the day than at night for Alligators A $\left(t_{41}=-2.32, \mathrm{p}<0.05\right), \mathrm{B}\left(t_{37}=\right.$ $-2.27, \mathrm{p}<0.005)$, and $\mathrm{D}\left(t_{38}=-2.11, \mathrm{p}<0.05\right.$; although this latter individual was mostly inactive), whereas day and night activity levels were not significantly different for Alligator $\mathrm{C}\left(t_{38}=0.23, \mathrm{p}=0.82\right)$.

GPS coordinates recorded for Alligator $\mathrm{C}$ showed that this alligator swam northward along the shore for the initial $3.5 \mathrm{~h}$ after its release and eventually stopped $1.5 \mathrm{~km}$ away from the release point (Fig. 3). The mean speed of the horizontal movements was $0.3 \mathrm{~m} \mathrm{~s}^{-1}$. The path was not straight, and included some loops and zigzags.

The mean air or water temperature experienced by the alligators was 24.3 to $27.4^{\circ} \mathrm{C}$ (Table 1).

\section{DISCUSSION}

We recorded the activity patterns of free-ranging American alligators. Our study is preliminary, descriptive, and based on a few individuals, so we were unable to examine various factors the could affect alligator behavior (e.g. season, age, sex). Nevertheless, the present study presents basic information for this species and will provide a basis for future studies seeking to record the behavior of crocodilians under natural conditions.

Crocodilians are often categorized as diving animals (Brischoux et al. 2008). However, the alligators tagged in this study did not dive deeper than their own body length, indicating that the American alligators in this study area are not true divers. This result was partly due to the shallow depths (approximately $<2 \mathrm{~m}$ ) of the area used by the animals, although some dredge holes of greater depths $(<8 \mathrm{~m})$ were within the animals' range. Our result is in contrast to freshwater crocodiles Crocodylus johnstoni, which often dive deeper than their own body length under natural conditions (Seebacher et al. 2005).

Crocodilians are generally sit-and-wait predators (Grigg \& Gans 1993). Therefore, the repeated inactive dives, interrupted by surfacings to breathe, observed in this study may represent a sit-and-wait strategy. If so, the repeated cycle (310 s submergence and 48 s surfacing, on average) may represent an optimal cycle, thus enabling the alligators to wait for prey in the water for as long as possible without relying heavily on anaerobic metabolism (which results in the accumulation of lactate in the blood and exponentially long post-dive surface intervals; Campbell et al. 2010a).

The short, periodic swimming events observed in this study indicates that alligators have low endurance capacities for swimming. Our result is consistent with the fact that, in general, reptiles frequently display short-term activity which are powered by anaerobic metabolism (Gatten 1985). This is in marked contrast to other air-breathing aquatic animals, including marine mammals, seabirds, and sea turtles, in which aquatic locomotion is mainly powered by aerobic metabolism (Kooyman 1989) and, thus, can be maintained for longer durations.

Although the alligators were active for only 2 to $29 \%$ of the time, their activity level inferred from acceleration records tended to be higher during the day than at night. This result partly reflects the fact that most diving and swimming activities were recorded during the day, and that even inactive dives include active periods, i.e. descent and ascent phases. Our results are consistent with those for freshwater crocodiles, which display more diving activity during the day than at night in their natural habitat (Seebacher et al. 2005). The diel activity patterns might be caused by higher solar radiation during the daytime, which raises the body temperature of the ani- 
mals (Seebacher et al. 2005). However, as Smith (1975) showed in a wildlife refuge, diel activity patterns of alligators might change seasonally. Alligators in captivity were reported to move between land and water according to the diel light cycle (Lang 1976). Unfortunately, we could not determine whether the animals were on land or in water unless they showed diving or swimming activities. Wet or dry sensors or more sensitive depth sensors are required to monitor the movements between land and water, and thus to better understand the diel activity patterns and behavioral thermoregulation of crocodilians in the wild.

The frequency of diving and swimming activities, as well as the percentage of active periods in a day, varied remarkably between individuals. This is in contrast to marine mammals, seabirds, and sea turtles, which often show similar activity patterns among conspecifics even over limited recording periods (e.g. Watanabe et al. 2004). Large inter-individual differences in the activity patterns of alligators may reflect individual hunting preferences or one way to avoid intra-specific competition, and warrant further investigation.

Large-scale movements (>10 km) of American alligators (Rosenblatt \& Heithaus 2011) and estuarine crocodiles Crocodylus porosus (Read et al. 2007, Campbell et al. 2010c) were previously recorded by acoustic telemetry or satellite-linked transmitters. Fine-scale movements within natural habitats, however, have never been studied for any crocodilians. We showed that the fine-scale movements of American alligators can be tracked by GPS tags. The path taken by one individual included loops and zigzags (Fig. 3), suggesting that the individual was searching for something (e.g. most likely prey). In future studies, longer deployment of GPS tags should reveal the alligators' searching movement within their natural habitat.

In conclusion, alligators displayed shallow, inactive dives and short, periodic swimming mostly in the daytime; however, inter-individual difference in behavior was remarkable. This study is the first step toward understanding the natural behavior of crocodilians, an understudied group among aquatic vertebrates.

Acknowledgements. We thank M. Legare and G. Burgess for logistical support, D. Buskill for assisting with fieldwork, and 2 anonymous reviewers for helpful comments on the draft. This work was funded by InnoMedic Health Applications, NASA, and Grants-in-Aids for Scientific Research from the Japan Society for the Promotion of Science (JSPS) (21681002).

\section{LITERATURE CITED}

Bondavalli C, Ulanowicz RE (1999) Unexpected effects of predators upon their prey: the case of the American alligator. Ecosystems 2:49-63

Brischoux F, Bonnet X, Cook TR, Shine R (2008) Allometry of diving capacities: ectothermy vs. endothermy. J Evol Biol 21:324-329

> Campbell HA, Dwyer RG, Gordos M, Franklin CE (2010a) Diving through the thermal window: implications for a warming world. Proc Biol Sci 277:3837-3844

> Campbell HA, Sullivan S, Read MA, Gordos MA, Franklin CE (2010b) Ecological and physiological determinants of dive duration in the freshwater crocodile. Funct Ecol 24: 103-111

Campbell HA, Watts ME, Sullivan S, Read MA, Choukroun S, Irwin SR, Franklin CE (2010c) Estuarine crocodiles ride surface currents to facilitate long-distance travel. J Anim Ecol 79:955-964

Craighead FC (1968) The role of the alligator in shaping plant communities and maintaining wildlife in the southern Everglades. Fla Nat 41:2-7, 69-74, 94

> Delany MF, Abercrombie CL (1986) American alligator food habits in northcentral Florida. J Wildl Manag 50:348-353

Farlow JO, Hurlburt G, Elsey RM, Britton ARC, Langston WL (2005) Femoral dimensions and body size of Alligator mississippiensis: estimating the size of extinct mesoeucrocodylians. J Vertebr Paleontol 25:354-369

Franklin CE, Read MA, Kraft PG, Liebsch N, Irwin SR, Campbell HA (2009) Remote monitoring of crocodilians: implantation, attachment and release methods for transmitters and data-loggers. Mar Freshw Res 60:284-292

Gatten RE (1985) The uses of anaerobiosis by amphibians and reptiles. Am Zool 25:945-954

Grigg GC, Gans C (1993) Morphology and physiology of the crocodylia. In: Glasby CJ, Ross GJB, Beesley PL (eds) Fauna of Australia, Vol 2A (Amphibia \& Reptilia). Australian Government Publishing Service, Canberra, p 326-336

Halsey LG, Shepard ELC, Quintana F, Gomez Laich A, Green JA, Wilson RP (2009) The relationship between oxygen consumption and body acceleration in a range of species. Comp Biochem Physiol A Mol Integr Physiol 152:197-202

Kooyman GL (1989) Diverse divers: physiology and behavior. Springer, Berlin.

Lang JW (1976) Amphibious behavior of Alligator mississippiensis: roles of a circadian rhythm and light. Science 191:575-577

Langley RL (2005) Alligator attacks on humans in the United States. Wilderness Environ Med 16:119-124

Naito Y (2004) New steps in bio-logging science. Mem Natl Inst Polar Res 58(Spec Issue):50-57

Read MA, Grigg GC, Irwin SR, Shanahan D, Franklin CE (2007) Satellite tracking reveals long distance coastal travel and homing by translocated estuarine crocodiles, Crocodylus porosus. PLoS ONE 2:e949

$>$ Rosenblatt AE, Heithaus MR (2011) Does variation in movement tactics and trophic interactions among American alligators create habitat linkages? J Anim Ecol 80:786-798

> Sakamoto KQ, Sato K, Ishizuka M, Watanuki Y, Takahashi A, Daunt F, Wanless S (2009) Can ethograms be automatically generated using body acceleration data from freeranging birds? PLoS ONE 4:e5379

> Seebacher F, Franklin CE, Read M (2005) Diving behaviour 
of a reptile (Crocodylus johnstoni) in the wild: interactions with heart rate and body temperature. Physiol Biochem Zool 78:1-8

Smith EN (1975) Thermoregulation of the American alligator, Alligator mississippiensis. Physiol Zool 48:117-194

Thorbjarnarson J (1999) Crocodile tears and skins: international trade, economic constraints, and limits to the sustainable use of crocodilians. Conserv Biol 13:465-470

Thorbjarnarson J, Wang X (1999) The conservation status of the Chinese alligator. Oryx 33:152-159

Watanabe Y, Baranov EA, Sato K, Naito Y, Miyazaki N

Editorial responsibility: Victor Benno Meyer-Rochow, Bremen, Germany
(2004) Foraging tactics of Baikal seals differ between day and night. Mar Ecol Prog Ser 279:283-289

Watanabe Y, Wei Q, Yang D, Chen X and others (2008) Swimming behavior in relation to buoyancy in an open swimbladder fish, the Chinese sturgeon. J Zool (Lond) 275:381-390

Wilson RP, White CR, Quintana F, Halsey LG, Liebsch N, Martin GR, Butler PJ (2006) Moving towards acceleration for estimates of activity-specific metabolic rate in freeliving animals: the case of the cormorant. J Anim Ecol 75:1081-1090

Submitted: November 2, 2012; Accepted: December 14, 2012 Proofs received from author(s): January 15, 2013 